\title{
Dyskeratosis Congenita in Siblings: A Rare Case Report
}

\section{Hemamalini Chandrashekhar ${ }^{1 *}$, Pallavi Ranadive ${ }^{2}$ and Mohan Deshpande $^{3}$}

${ }^{1}$ Oral and Maxillofacial Surgeon, Dental Solutions, Former Post Graduate Resident, Department of Oral and Maxillofacial Surgery, Nair Hospital Dental College,

Mumbai, India

${ }^{2}$ Associate Professor (Additional), Department of Oral and Maxillofacial Surgery,

Nair Hospital Dental College, Mumbai, India

${ }^{3}$ Professor, Department of Oral and Maxillofacial Surgery, Nair Hospital Dental

College, Mumbai, India

*Corresponding Author: Hemamalini Chandrashekhar, Oral and Maxillofacial

Surgeon, Dental Solutions, Former Post Graduate Resident, Department of Oral and Maxillofacial Surgery, Nair Hospital Dental College, Mumbai, India.
Received: October 28, 2021

Published: November 23, 2021

(C) All rights are reserved by Chandrashekhar

H., et al.

\section{Abstract}

Dyskeratosis congenita (DC) is a rare telomere disorder presenting with distinct clinical and genetic heterogeneity. The classical DC comprises of a triad- skin pigmentation, nail dystrophy and oral leucoplakia. However, DC can manifest with a variety of multiorgan involvement, mainly the haemopoetic, respiratory and gastrointestinal. Predisposition to cancers and bone marrow failure are often the reasons for early mortality. Oral findings of DC include rampant dental caries, periodontal disease and taurodontism.

In this paper, we present a rare case report of Dyskeratosis Congenita in two siblings of opposite gender. This case report mainly aims to address the challenges in diagnosing this rare condition, by revisiting its clinical features, particularly the oral manifestations. It is also intended to supplement data of DC in females, in whom the condition is extremely rare.

Keywords: Dyskeratosis Congenita; Pre-cancerous Condition; Telomere Disorder; Zinsser-Cole-Engman Syndrome

\section{Introduction}

Dyskeratosis Congenita (DC) is a rare, inherited, pre- malignant condition. It was first described by Zinssor., et al. in 1910, hence the name, Zinssor-Cole-Engman Syndrome [1]. DC is a disease of short telomere with an incidence of 1 in a million [2,3]. The condition is inherited as X-linked recessive (XLR) disorder with male: female predilection of 13:1 [3-6].

Patients with DC have abnormally short telomere and defective telomere maintenance, thus leading to a multi-system disorder [2,3]. However, 30-40\% have no detectable mutations [3]. DC classically presents with skin pigmentation (89\%), nail dystrophy $(88 \%)$ and oral leucoplakia (78\%) [1,3]. Improved understanding of genetics has led to the unification of DC with several severe multisystem disorders like Hoyeraal-Hreidarsson and Revesz syndromes, as well as some subset of patients affected with aplastic anemia, myelodysplasia, leukemia, and idiopathic pulmonary fibrosis $[3,5]$. Thus, the diagnosis of this condition is quite challenging and needs understanding its wide clinical spectrum. DC is most often diagnosed by paediatricians, dermatologists or haematologists, but occasionally, oral clinicians may be the primary diagnosticians. 
The authors report a case of Dyskeratosis Congenita in two siblings. The paper aims to discuss the clinical manifestations and treatment considerations of DC, thus aiding in creating awareness among oral clinicians about this rare genetic condition.

\section{Case 1}

A 20-year-old female presented with intraoral growth on the right side of the lower jaw (Figure 1). The intra- oral lesion was a white, fibrous, hyperkeratotic growth extending over the edentulous mandibular alveolus. A significant alveolar bone loss (width and height) was seen. The overall oral hygiene was poor with multiple carious and missing teeth, and deep periodontal pockets.

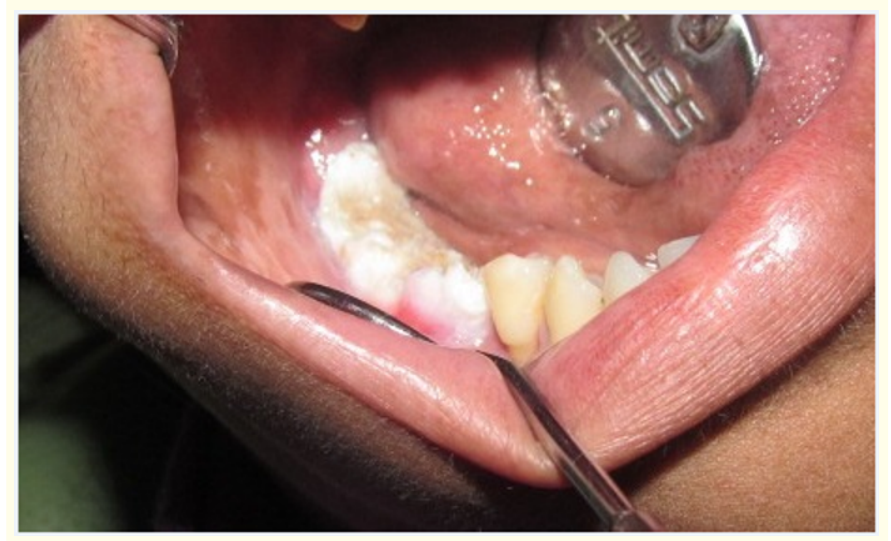

Figure 1: Hyperkeratotic lesion in right buccal vestibule and alveolus.

Physical examination revealed presence of greyish reticular pigmentation on the extremities bilaterally, with chipped or absent finger and toe nails (Figure 2). She gave history of learning disabilities (discontinued studies after middle school), menstrual irregularities (since menarche) and meningeal tuberculosis 2 years ago (treated with anti-tubercular drugs). Based on the history and clinical findings, patient was suspected of Dyskeratosis Congenita. Her haematological picture was normal and in view of the same, bone marrow examination was deferred.

After due informed consent, excision of the intraoral growth (Figure 4) was performed under local anaesthesia. The histopathology report showed features of verrucous hyperplasia.

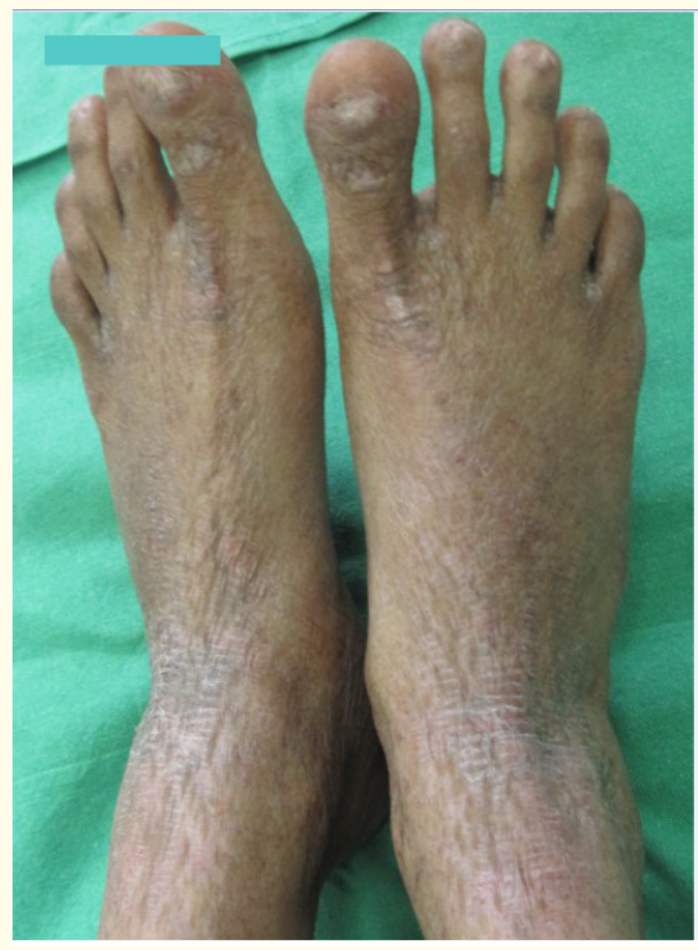

Figure 2: Premature aging and reticular pigmentation of the skin along with absence of toe nails.

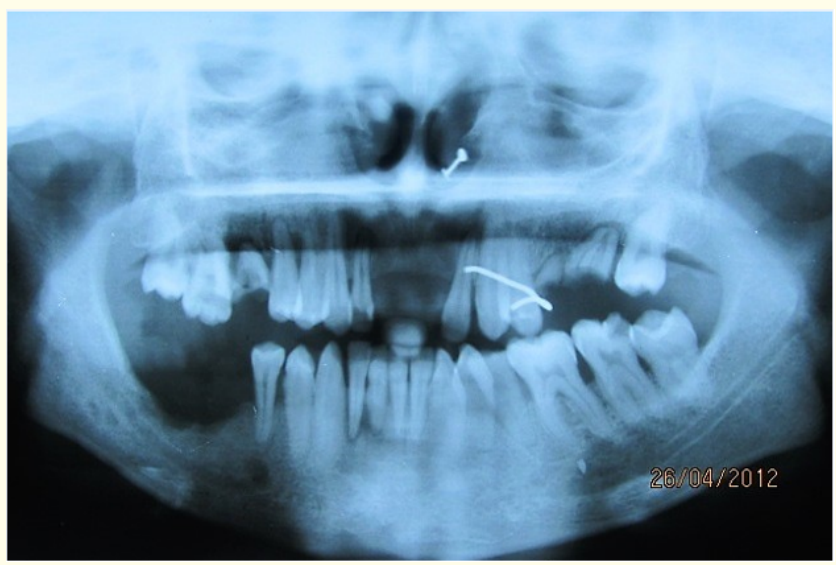

Figure 3: OPG showing erosion of the alveolar bone on right posterior mandible, rampant caries, poor periodontal condition with generalized loss of alveolar bone. 


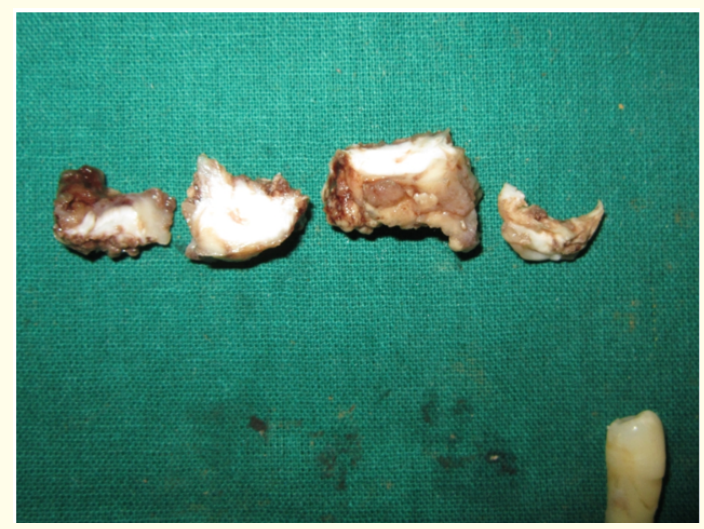

Figure 4: Excised intra-oral specimen with associated teeth.

\section{Case 2}

The female patient's younger sibling, 18- year old male, also showed similar clinical features- skin pigmentation and absence of finger and toe nails. The intraoral examination revealed presence of red and white leucoplakia (Figure 6) on the hard palate completing the classical triad of Dyskeratosis Congenita. Other oral findings were quite similar to his siblings (Table 2). He was a nonsmoker and his medical history was not contributory and blood investigations were normal. As the oral lesion was asymptomatic and non-suspicious, biopsy was deferred.

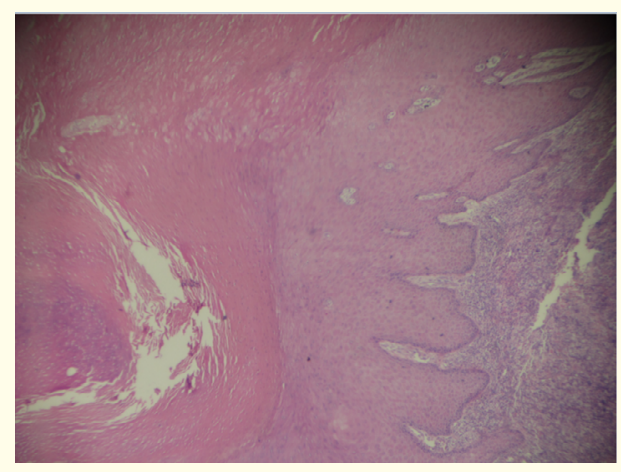

Figure 5: Histopathology- H\&E stained section shows dysplastic, hyperkeratotic, highly proliferative stratified squamous epithelium with blunt and pointed surface projections. The rete pegs were blunt and placed almost at the same level. Epithelium showed basal cell hyperplasia, acanthosis and hyperchromatic nuclei. Underlying connective tissue had intense chronic inflammatory cell infiltrate. Basement membrane was intact.

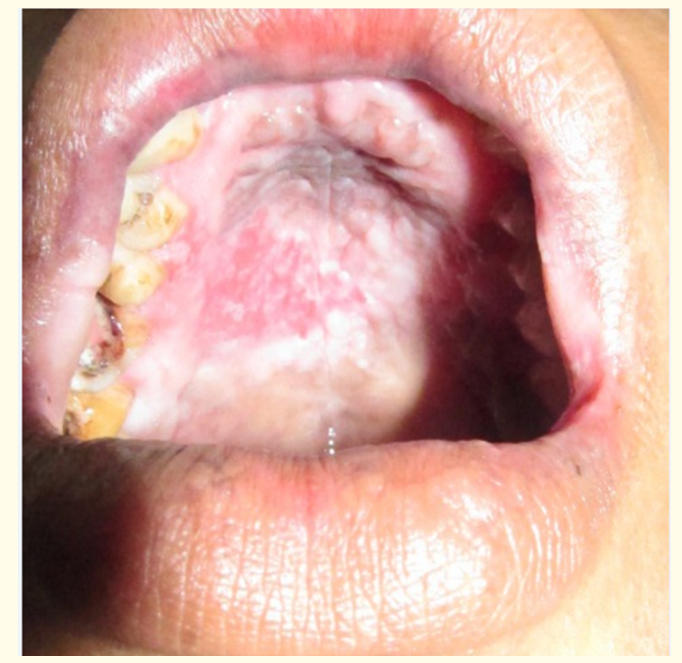

Figure 6: Leukoplakia on the hard palate in the male patient.

Their family history revealed that their parents had consanguineous marriage. Their mother aged 52 had no known medical conditions but the siblings revealed had nail dystrophy and pigmentations similar to them. They also reported that their father had suffered advanced oral cancer and died by the age of 40 years. The siblings were counselled to undergo genetic testing, but they refused claiming financial burden and fear of social stigma. The patients were followed up for 2 years, but later were lost to follow- up.

\section{Discussion}

Dyskeratosis congenita is a premature aging syndrome with a range of other abnormalities, including early greying, dental loss, osteoporosis, and malignancy. Dyskeratosis congenital (DC) was the first disorder to be linked to a mutant telomere gene and is an inherited bone marrow failure syndrome $[3,5]$. Eleven genes have been identified to cause short telomere- ACD, CTC1, DKC1, NHP2, NOP10, PARN, RTEL1, TERC, TERT, TINF2, NOLA2, NOLA3 and WRAP53 $[3,5,6]$. However, these genes make up approximately $70 \%$ of DC $[3,5]$. There are three modes of inheritance of DC. The XLR (40\%), autosomal dominant (5\%) and autosomal recessive $(<1 \%)$.

A classical DC presents with the triad of skin pigmentation, nail dystrophy and oral leucoplakia (OLP). But, majority of the diagnosis is based on presence of a minimal clinical criterion of atleast 
two major and two or more minor features, presented in table 1 [7]. The clinical features of both the patients are presented in table 2 . In both siblings, the pigmentation started by the age of 10-11 years, as typically seen in DC. The female reported history of meningeal tuberculosis, correlating to an increased susceptibility of infections, found in DC patients $[5,8,9]$.

\begin{tabular}{|c|c|}
\hline Major clinical features & $\begin{array}{l}\text { Approximate } \% \\
\text { of patients }\end{array}$ \\
\hline \multicolumn{2}{|l|}{ Mucocutaneous triad } \\
\hline Abnormal skin pigmentation & 89 \\
\hline Nail dystrophy & 88 \\
\hline Leukoplakia & 78 \\
\hline Bone marrow failure & 85.5 \\
\hline \multicolumn{2}{|l|}{$\begin{array}{l}\text { Other recognized somatic fea- } \\
\text { tures (Minor) }\end{array}$} \\
\hline Epiphora & 30.5 \\
\hline $\begin{array}{l}\text { Learning difficulties/develop- } \\
\text { mental delay/mental retardation }\end{array}$ & 25.4 \\
\hline Pulmonary disease & 20.3 \\
\hline Short stature & 19.5 \\
\hline Extensive dental caries/loss & 16.9 \\
\hline Esophageal stricture & 16.9 \\
\hline $\begin{array}{c}\text { Premature hair loss/greying/ } \\
\text { sparse eyelashes }\end{array}$ & 16.1 \\
\hline Hyperhiderosis & 15.3 \\
\hline Malignancy & 9.8 \\
\hline Intrauterine growth retardation & 7.6 \\
\hline $\begin{array}{l}\text { Liver disease/peptic ulceration/ } \\
\text { enteropathy }\end{array}$ & 7.3 \\
\hline Ataxia/cerebellar hypoplasia & 6.8 \\
\hline $\begin{array}{c}\text { Hypogonadism/undescended } \\
\text { testes }\end{array}$ & 5.9 \\
\hline Microcephaly & 5.9 \\
\hline Urethral stricture/phimosis & 5.1 \\
\hline $\begin{array}{l}\text { Osteoporosis/aseptic necrosis/ } \\
\text { scoliosis }\end{array}$ & 5.1 \\
\hline Deafness & 0.8 \\
\hline
\end{tabular}

Table 1: Multisystem clinical features of dyskeratosis congenital $[3,5]$.

\begin{tabular}{|c|c|c|c|}
\hline & & $\begin{array}{c}\text { Case } 1 \\
\text { (Female) }\end{array}$ & $\begin{array}{l}\text { Case } 2 \\
\text { (Male) }\end{array}$ \\
\hline \multirow[t]{4}{*}{ Major } & Skin Pigmentation & Y & Y \\
\hline & Nail dystrophy & Y & Y \\
\hline & Oral leukoplakia & $\mathrm{N}$ & Y \\
\hline & Bone marrow failure & NA & NA \\
\hline \multirow[t]{9}{*}{ Minor } & Extensive dental caries & Y & Y \\
\hline & Periodontitis & Y & Y \\
\hline & Premature greying of hair & Y & Y \\
\hline & Hyperhidrosis & $\mathrm{N}$ & $\mathrm{N}$ \\
\hline & Pulmonary disease & $\mathrm{Y}$ (in past) & $\mathrm{N}$ \\
\hline & Oral Hyperkeratosis & $\mathrm{Y}$ & $\mathrm{N}$ \\
\hline & Hypodontia & $\mathrm{Y}$ & $\mathrm{Y}$ \\
\hline & Alveolar bone loss & Y & $\mathrm{Y}$ \\
\hline & $\begin{array}{l}\text { Decreased root/crown ratio } \\
\text { in at least } 4 \text { posterior teeth }\end{array}$ & $\mathrm{Y}$ & Y \\
\hline \multicolumn{4}{|c|}{ Y- yes; N- No; NA- Not Assessed. } \\
\hline
\end{tabular}

Table 2: Major and Minor Clinical features of DC in the presented patients.

DC has a fifty-fold greater risk to malignancies of head and neck squamous cell carcinoma, cervical squamous cell carcinoma, non- Hodgkin lymphoma, myelodysplastic syndrome and basal cell carcinoma $[3,8]$. OLP is seen in 65 to $80 \%$ of DC and carries up to 1000 -fold greater risk of malignant transformation $[5,8]$. Other oral findings seen in DC include decreased root/crown ratio (75\%) taurodontism (57\%), extensive caries (17\%), hypodontia (12.5\%), alveolar bone loss and aggressive periodontitis [9].

Bone marrow failure (BMF) occurs in DC within the age of 30 years. BMF (90\%) pulmonary diseases (15\%) and malignancies $(10 \%)$ are also the major causes of early mortality $[5,7,8]$.

Hoyeraal-Hreidarsson syndrome (HHS) and Revesz syndrome (RS) are considered severe variants of DC $[3,5,7]$. In addition to the features of DC, HHS shows developmental delay, immunodeficiency and cerebellar hypoplasia and RS presents with bilateral exudative retinopathy. Both these syndromes display shorter telomeres than individuals with classic DC. 
Management of DC

The treatment of DC is usually symptomatic and a multi- disciplinary team (MDT) approach is ideal for better outcomes. Longterm follow-up forms the cornerstone of management of DC. Genetic testing and counselling of the patient and their family is important. However, like some other Asian countries, in India too, it is fairly common for patients to present for consultation at advanced stages of diseases and deny genetic testing of themselves or family members. This can be attributed to the lack of awareness, lack of medical facilities or treatment funds/insurance, and social stigma associated with the diagnosis of a hereditary disease [11]. Thus it is imperative that the management of DC not only addresses the medical issues but also addresses the psychological and socio-cultural issues. Preventive annual screening inclusive of clinical examination, blood and pulmonary function tests form an integral part of medical care [7]. Bone marrow biopsies should be restricted to abnormal blood tests $[3,5,7]$. In case the patient needs surgery, there are no known contra-indications for the use of local anaesthesia, however, for procedures under general anaesthesia, the patient should be screened additionally for BMF-related pancytopenia, difficult airway and opportunistic infections $[1,9,10]$. It is advisable to schedule the surgery when the patient's clinical and laboratory parameters are optimal and prophylactic antibiotics may be necessary [10].

\section{Conclusion}

DC is a multi- system disorder and can present with wide clinical variations making the diagnosis and treatment often challenging. Genetic testing aids in detecting appropriate mutations confirming the diagnosis. However, in middle and low-economic countries, due to lack of funds and diagnosing facilities, diagnosis is often based on clinical evaluations. Hence, it is important that clinicians and dentists be cognisant of the clinical features, diagnosis and management of such rare conditions for optimal patient care.

\section{Funding}

The publication did not receive funds from any sources.

\section{Conflict of Interest}

None.

\section{Ethical Approval}

This article does not contain experimental study with human participants.

\section{Informed Consent}

Informed consent was obtained.

\section{Author Declaration}

We confirm that the manuscript has been read and approved by all named authors and that there are no other persons who satisfied the criteria for authorship but are not listed. We further confirm that the order of authors listed in the manuscript have been approved by all of us.

\section{Bibliography}

1. Karunakaran A., et al. "Dyskeratosis congenita: a report of two cases". Case Reports in Dentistry (2013): 845125.

2. Z Noto K., et al. "Dyskeratosis congênita associated with leukoplakia of the tongue". International Journal of Oral and Maxillofacial Surgery (2016): 760-763.

3. Dokal I. "Dyskeratosis congenita". The American Society of Hematology Education Program (2011): 480-486.

4. Ogden GR. "Dyskeratosis congenita: report of a case and review of the literature". Oral Surgery, Oral Medicine, Oral Pathology, and Oral Radiology 65.5 (1988): 586-591.

5. Fernández García MS and Teruya-Feldstein J. "The diagnosis and treatment of dyskeratosis congenita: a review". Journal of Blood Medicine 21.5 (2014): 157-167.

6. Garofola C., et al. "Dyskeratosis Congenita". StatPearls. Treasure Island (FL): StatPearls Publishing (2021).

7. Savage SA. “Dyskeratosis Congenita”.In: Gene Reviews ${ }^{\circledR}$ Seattle (WA): University of Washington, Seattle (2016): 1993-2018.

8. Bongiorno M., et al. "Malignant transformation of oral leukoplakia in a patient with dyskeratosis congenita". Oral Surgery, Oral Medicine, Oral Pathology, and Oral Radiology (2017): e239-e242.

9. Koruyucu M., et al. "Oral and Dental Findings of Dyskeratosis Congenita". Case Reports in Dentistry (2014): 454128. 
Dyskeratosis Congenita in Siblings: A Rare Case Report

10. Anestezi DKBH. "Anesthetic Management in a Case of Dyskeratosis Congenita". Anatolian Clinic Journal of Medical Sciences (2018): 48-50.

11. Ratnasamy V., et al. "Dyskeratosis congenita with a novel genetic variant in the DKC1 gene: a case report". BMC Medical Genetics 19.1 (2018): 85.

Volume 5 Issue 12 December 2021

(C) All rights are reserved by Chandrashekhar H., et al. 